\title{
Automated identification of construction works and structural elements at an early stage of investment and construction projects' implementation
}

\author{
Alexander Ginzburg and Ilya Tyurin* \\ Moscow State University of Civil Engineering, Yaroslavskoe shosse, 26, Moscow, 129337, Russia
}

\begin{abstract}
The article discusses the issues of construction objects pricing in terms of the formation of certain types of costs and an analysis of their interrelationships based on the generated data bank of design and estimate documentation of implemented state investment construction projects. Special attention is paid to the research of the impact of changes in design solutions on the cost of construction. Approaches to the reorganization of the established design technology are proposed. These approaches use automated identification of construction work and structural elements based on the method for assigning criteria for the selection of building structures that are supposed to be erected around the technological space specified by the customer. The selection criteria established in this way assist designers in finding optimal design solutions for the subsequent development of working documentation.
\end{abstract}

\section{Introduction}

A significant rise of modern computer technology capabilities leads to the trend of increasing the level of automated processes in the design of building objects [1]. The first development of computer-aided design (CAD) systems began after World War II and should control the forces and means of continental air defense. Further development of CAD took place in industrial design which was widely used in the automotive, shipbuilding and aerospace industries. The arrival of CAD in the construction industry from related production areas, reduced the question of automation to the problem of choosing automation of human functions in investment and construction projects. This is because of the development of software products on the principle of complementarity between man and technology [2].

The modern direction of CAD development in the construction industry is the "building information modeling" (BIM) approach, which is based on the use of a single building model and the exchange of information storage about any object by all participants throughout the life cycle of the investment and construction project $[3,4,5]$. Designers

*Corresponding author: TyurinIA@mgsu.ru 
have and will continue to have new tools for automation of their activities [6], designing a single facility, now the best engineers distributed throughout the country can deal with it, and also, more and more often, it is practiced to attract foreign specialists. BIM technology is not limited to solving problems related to design, but also allows management of construction deals with the issues of time organization of the construction process including logistical support, well-timed delivery of construction material, carcasses and goods to warehouses and construction sites [7,8] and at the operational stage too [9]. Despite these colossal innovations, the conservatism of designers, because of the high standardization of their activities, does not allow the design system to develop in full [10]. The modern design process is a traditional well-established design method, saturated with all kinds of information technologies.

Estimated activity also goes along the path of automating the processes performed by estimate engineers in the design system that has developed over the years [11]. At the early stages of implementing investment and construction projects, many approaches are undergone to determine the estimated cost of construction [12], such as:

- calculating the cost based on analogous facilities,

- using collections of construction price standards,

- modeling cost based on price data accumulated during the construction of similar facilities.

Even with the full automation of the listed methods for determining the estimated cost of construction, all these methods are aimed at assessing the cost of an object planned for construction and do not make it possible to influence the cost in the further development of a construction project.

To determine the ability of customers to manage construction costs in the early stages of investment and construction projects, the component costs were considered. The cost of construction of facilities was presented in the following form [13]:

$$
S_{I C P}=C_{S M R}+C_{T O}+C_{U S}
$$

here:

$\mathbf{S}_{\mathrm{ICP}}$ - the cost of implementing an investment and construction project;

$\mathbf{C}_{\mathrm{SMR}}$ - construction and installation costs;

$\mathbf{C}_{\mathrm{TO}}$ - the cost of purchasing technological equipment;

$\mathbf{C}_{\mathrm{US}}$ - other customer costs associated with construction conditions, the formation of a reserve of funds for unforeseen expenses, the contractor's normative profit, and so on.

The cost of purchasing technological equipment $\left(\mathbf{C}_{\mathrm{TO}}\right)$ depends on the functional and technological purpose of the construction object and is not related to design decisions made by design engineers. For example, the type of densitometer and the type of a dental chair for equipping a dentist's office do not depend on the configuration and spatial position of the room in the building. It is also obvious that the variability of the design decisions taken does not significantly affect the costs associated with construction conditions $\left(\mathbf{C}_{\mathrm{US}}\right)$, such as the acquisition of a land plot, the supply of external engineering networks, and so on. Thus, we can conclude that the change in the cost of an investment and construction project depends only on the costs associated with the implementation of construction and installation works $\mathbf{S}_{\mathrm{ICP}}\left(\mathbf{C}_{\mathrm{SMR}}\right)$, and the costs of $\mathrm{C}_{\mathrm{TO}}$ and $\mathrm{C}_{\mathrm{US}}$ can be assumed unchanged: $\mathbf{C}_{\mathrm{TO}(\mathrm{const})}$ and $\mathbf{C}_{\mathrm{US} \text { (const) }}$ respectively. Further, the composition of the construction costs and installation works was considered $\left(\mathbf{C}_{\mathrm{SMR}}\right)$ :

$$
C_{S M R}=C_{W}+C_{L I M}+C_{I O}
$$

here:

$\mathbf{C}_{\mathrm{W}}-$ costs of performing general construction works;

$\mathbf{C}_{\mathrm{LIM}}-$ costs associated with the organization of construction and installation works and construction conditions; 
$\mathbf{C}_{\mathrm{IO}}-$ costs associated with the arrangement of engineering support.

In Russia, the costs associated with the organization of construction and installation work and construction conditions (overhead costs and contractor's profit, the rise in cost due to work in the winter, remoteness of the construction site from settlements, etc.) are determined using collections of coefficients "limited costs" $\left(\mathbf{K}_{\mathrm{LIM}}\right)$ [13], which apply to the costs of performing general construction works $\left(\mathbf{C}_{\mathrm{W}}\right)$, and depend on the specific $\mathbf{i}$-th type of work and the region of construction $\left(\mathbf{k}_{\mathrm{LIM}(\mathrm{reg})}\right)$, then for the set of considered construction and installation works (I):

$$
C_{W}+C_{L I M}=\sum_{i=1}^{I}\left(C_{W i} \cdot k_{L I M i}\right) \cdot k_{L I M(r e g)}
$$

The analysis of the costs associated with the engineering support device $\left(\mathbf{C}_{\mathrm{IO}}\right)$ showed that their value is influenced only by the total indicators of the energy demand of the construction object, such as water consumption, wastewater disposal, electricity demand, and the number of final energy consumers. The change in the spatial position of the end users of energy resources in the building, to a large extent, does not affect the change in the amount of costs associated with the engineering support device $\left(\mathbf{C}_{\mathrm{IO}}\right)$. In this regard, the amount of costs for the device of engineering support of the building was taken as a constant value $\left(\mathbf{C}_{\mathrm{IO}} \Rightarrow \mathbf{C}_{\mathrm{IO} \text { (const) }}\right)$. As a result, formula (2) took the form:

$$
C_{S M R}=\sum_{i=1}^{I}\left(C_{W i} \cdot k_{L I M i}\right) \cdot k_{L I M(\text { reg })}+C_{I O(\text { const })}
$$

From formula (4) the amount of construction and installation work $\left(\mathbf{C}_{\mathrm{SMR}}\right)$ costs is affected only by the costs of performing general construction work $(\mathrm{CW})$, which can be represented in the following form:

$$
C_{W}=\sum_{i=1}^{I}\left(C_{M R O W i}+C_{M M i}+C_{P F i}\right)
$$

here:

$\mathbf{C}_{\text {MROWi }}$ - costs associated with the acquisition of material resources for the $\mathbf{i}$-th type of general construction work;

$\mathbf{C}_{\mathrm{MMi}}-$ costs associated with the use of construction machines and mechanisms for the i-th type of general construction work;

$\mathbf{C}_{\mathrm{PFi}}$ - the costs of the formation of the wage fund for the $\mathbf{i}$-th type of general construction work;

I - number of general constructions works under consideration.

Using collections of Russian state estimate norms makes it possible to make the following expressions dependent: $\mathbf{C}_{\mathrm{MM}}\left(\mathbf{C}_{\mathrm{MROW}}\right), \mathbf{C}_{\mathrm{PF}}\left(\mathbf{C}_{\mathrm{MROW}}\right)$ and present them as coefficients applied to the costs of material resources $\mathbf{k}_{\mathrm{MM}}$ and $\mathbf{k}_{\mathrm{PF}}$, respectively. Then formula (5) takes the following form:

$$
\begin{aligned}
& C_{W}=\sum_{i=1}^{I}\left(C_{M R O W i}+C_{M R O W i} \cdot k_{M M i}+C_{M R O W i} \cdot k_{P F i}\right)= \\
& =\sum_{i=1}^{I}\left[C_{M R O W i} \cdot\left(1+k_{M M i}+k_{P F i}\right)\right]
\end{aligned}
$$

As a result, the general cost model of construction (1) will take the following form:

$$
\begin{aligned}
& S_{I S P}=\sum_{i=1}^{I}\left[C_{M R O W i} \cdot\left(1+k_{M M i}+k_{P F i}\right)\right] \cdot k_{L I M(\text { reg })}+ \\
& +C_{I O(\text { const })}+C_{T O(\text { const })}+C_{U S(\text { const })}
\end{aligned}
$$


As it can be seen from formula (7), the resulting cost model allows us to manage the cost of construction by changing (selecting) the material resources of general construction works $\left(\mathbf{C}_{\text {MrOwi }}\right)$, the remaining components are expressed as coefficients or are constant, regardless of the design decisions made.

The developed cost model allows the participants of investment and construction projects to manage the cost of construction, but the use of the model without automation is very difficult. It is advisable to automate the proposed model with the existing developments in the automated identification of construction work and structural elements $[14,15]$.

\section{Determination of the automation task}

Having analyzed the formation of the cost of implementing investment and construction projects, the selection of material resources for performing general construction work can be carried out before the development of project documentation, namely in forming a technical assignment for design. To study the principles of the formation of technical specifications for implementing design work, a sample was made from 1130 construction objects of the state order. The selection was carried out by grouping objects according to technological purpose, a base of schools, kindergartens, residential buildings, and so on was formed. In total, 42 groups were formed, with the number of objects in each, at least five. The result of studying the technical specifications from the got sample of constructed objects showed that when forming technical specifications, customers specify the requirements for the technological spaces, according to two principles:

- the principle of minimizing the erected building structures around a given technological space $\left(\mathbf{V o l}_{\min }\right)$;

- the principle of maximizing the technological space inside building structures, limited by construction conditions $\left(\mathbf{V o l} \mathbf{l}_{\max }\right)$.

When forming a technical assignment, customers pursue a goal, or as much as possible to reduce the volume of building structures (construction work), for example, educational and medical institutions; or, conversely, to maximize the technological space that fits into the building structures (maximizing the area of apartments in housing development).

Information about technological spaces is most often presented as tables containing areal and height characteristics. When comparing the values of the areas of the premises specified in the terms of reference with the values got because of the design work, average deviations $\left(\mathbf{K}_{\mathrm{SQ}}\right)$ were revealed in the amount of $+5.1 \%$ and $-4.9 \%$ for $\mathbf{V o l} \mathbf{l}_{\min }$ and $\mathbf{V o l} \mathbf{l}_{\max }$, respectively. These deviations, mostly, are associated with ensuring compliance with fire safety requirements and the availability of architectural and stylistic solutions (complex shape of the building, decorative superstructures, etc.). Thus, because of the study, it became possible to predict deviations of designers from the technical specifications, because of the development of space-planning solutions.

Having data on the characteristics of technological spaces and having the ability to predict deviations of designers from the technical task, automation can be reduced to the development of a method for finding and assigning technological spaces, parameters of general construction works necessary for their inclusion in building structures.

\section{Methodology}

To solve incrementing the costs of general construction work on technological spaces, the following link was considered: technological spaces - building structures - costs of general construction works. For the parametric description of the erected structures of buildings, 
weighty building elements, such as a facade $\left(\mathbf{S K}_{\mathrm{FD}}\right)$, a supporting frame $\left(\mathbf{S K}_{\mathrm{KS}}\right)$ and a foundation $\left(\mathbf{S K}_{\mathrm{FT}}\right)$, were singled out in a separate group, since they do not have the requirements for enclosing a technological space in building structures of single premises (SK $\mathbf{T E X}_{\mathrm{TEX}}$ and considered for the building generally. Building structures, the construction costs of which are constant regardless of the design decisions taken $\left(\mathbf{C}_{\mathrm{TO}(\mathrm{const})}, \mathbf{C}_{\mathrm{US}(\mathrm{const})}\right)$ $\left.\mathbf{C}_{\mathrm{IO}(\text { const) }}\right)$, were also allocated to a separate group $\left(\mathbf{S K}_{\text {(const) }}\right)$. According to the accepted designations, the parametric description of the composition of building structures $\left(\mathbf{S K}_{\mathrm{BNG}}\right)$ is as follows:

$$
S K_{B N G}=S K_{K S}+S K_{F T}+S K_{F D}+\sum_{i=1}^{I} S K_{T E X i} \cdot K_{S Q}+S K_{(\text {const })}
$$

The parametric description of the supporting frame $\left(\mathbf{S K}_{\mathrm{KS}}\right)$ was carried out based on empirical data got because of the study of analogous objects, by comparing the area of vertical structures with the amount of material resources required for the construction of floors. In the process of research, regularities were identified between the cross-section of columns / walls / pylons with a comparison of their filling density per $1000 \mathrm{~m} 2$ and the required volume of building materials for the construction of floors. The parametric description of building foundation structures $\left(\mathbf{S} \mathbf{K}_{\mathrm{FT}}\right)$ was carried out by analogy with $\mathbf{S K}_{\mathrm{KS}}$, by comparing the volume and number of stores of the building with it's area. The parametric description of the building façade $\left(\mathbf{S K}_{\mathrm{FD}}\right)$ was based on the type of structure (ventilated façade, plaster façade, etc.). The parametric descriptions of $\mathbf{S} \mathbf{K}_{\mathrm{KS}}, \mathbf{S} \mathbf{K}_{\mathrm{FT}}$ and SK $_{\mathrm{FD}}$ resulted construction worksheets compiled based on collections of Federal unit rates.

To solve the problem of selection of construction works and structural elements for the given technological space, the classification of building structure elements was carried out according to the characteristics of $\mathbf{P}_{\mathrm{j}}$. The study used three main features:

$$
\begin{aligned}
& \mathbf{P}_{1}-\text { «decorative»; } \\
& \mathbf{P}_{2} \text { - «functional»; } \\
& \mathbf{P}_{3} \text { - «filling». }
\end{aligned}
$$

The elements on the "decorative" basis included materials of visible surfaces and decorative structures, for example: painting, suspended ceiling, linoleum. According to the "functional" feature, the elements were classified as materials that must have a certain functional purpose, for example: fire retardant coatings, thermal insulation.

The elements according to the "filling" feature were materials and structures that separate different technological processes, for example: non-load-bearing partitions, leveling screeds, backfilling. The $\mathbf{P}_{1}$ feature was determined by the following criteria: $\mathbf{K}_{\mathrm{SMP}}$ - type of coating material; $\mathbf{K}_{\mathrm{FRC}}$ - perceived loads; $\mathbf{K}_{\mathrm{EX}}$ - operating conditions; $\mathbf{K}_{\mathrm{UNC}}$ is a unique criterion. $\mathbf{P}_{2}$ is defined by the following criteria: $\mathbf{K}_{\mathrm{TP}}$ - thermal conductivity, $\mathbf{K}_{\mathrm{ZHS}}$ noise protection, $\mathbf{K}_{\mathrm{PB}}$ - fire safety, $\mathbf{K}_{\mathrm{UNC}}$ - a unique criterion. Characteristic $\mathbf{P}_{3}$ is defined by the following criteria: $\mathbf{K}_{\mathrm{SMZ}}$ - type of filling material, $\mathbf{K}_{\mathrm{UNC}}$ - unique criterion.

The introduction of a unique criterion $\left(\mathbf{K}_{\mathrm{UNC}}\right)$ for all features was due to the impossibility of finding an appropriate justification for individual customer requirements. Requirements for the conclusion of technological spaces in building structures were expressed in the following form:

$$
S K_{\text {TEXi }}=F_{\text {TEXi }}\left(\sum_{j=1}^{J} P_{j}\right)+R_{\text {TEXi }}\left(\sum_{j=1}^{J} P_{j}\right)+W_{T E X i}\left(\sum_{j=1}^{J} P_{j}\right)
$$

here:

SK $_{\mathrm{TEXi}}$ - building structures of the $\mathbf{i}$-th technological space;

$\mathbf{F}_{\mathrm{TEXi}}-$ floor structures of the $\mathbf{i}$-th technological space with features $\mathbf{P}_{\mathrm{j}}$;

$\mathbf{R}_{\mathrm{TEXi}}-$ ceiling structures of the $\mathbf{i}$-th technological space with features $\mathbf{P}_{\mathrm{j}}$;

$\mathbf{W}_{\mathrm{TEXi}}-$ wall structures of the $\mathbf{i}$-th technological space with the features $\mathbf{P}_{\mathrm{j}}$; 
I - the total number of technological spaces (rooms);

$\mathbf{J}$ - number of signs for identification.

In general, the developed technique can be written as follows:

$$
\begin{aligned}
& S K_{B N G}=S K_{K S}+S K_{F T}+S K_{F D}+S K_{(\text {const })}+ \\
& +\sum_{i=1}^{I}\left[F_{T E X i}\left(\sum_{j=1}^{J} P_{j}\right)+R_{T E X i}\left(\sum_{j=1}^{J} P_{j}\right)+W_{T E X i}\left(\sum_{j=1}^{J} P_{j}\right)\right] \cdot K_{S Q}
\end{aligned}
$$

For example, the automated identification of construction works and structural elements according to the developed method for the technological space "meeting room", with an area of $28 \mathrm{~m} 2$ and with the requirements: floor - carpet, ceiling - soundproof, trimmed with panels, walls - wallpapering and the principle of minimizing building structures under construction around a given technological space is as follows:

$$
\begin{aligned}
& \boldsymbol{S K}_{\text {MEETRM }}=\boldsymbol{F}_{\text {MEETRM }}\left(\boldsymbol{P}_{1}(\text { carpet, } 0,0,0)+\boldsymbol{P}_{2}(0,0,0,1)+\boldsymbol{P}_{3}(0,0)\right) \cdot \boldsymbol{K}_{S Q}\left(\boldsymbol{V o l}_{\text {min }}\right)+ \\
& \left.\quad+\boldsymbol{R}_{\text {MEETRM }}\left(\boldsymbol{P}_{1} \text { (s.ceiling, } 0,0,0\right)+\boldsymbol{P}_{2}(0,1,0,0)+\boldsymbol{P}_{3}(0,0)\right) \cdot \boldsymbol{K}_{S Q}\left(\boldsymbol{V o l}_{\text {min }}\right)+ \\
& \left.\quad+\boldsymbol{W}_{\text {MEETRM }}\left(\boldsymbol{P}_{1} \text { (w.paper, } 0,0,0\right)+\boldsymbol{P}_{2}(0,1,0,0)+\boldsymbol{P}_{3}(\text { light }, 0)\right) \cdot \boldsymbol{K}_{S Q}\left(\boldsymbol{V o l}_{\text {min }}\right)
\end{aligned}
$$

The result of the identification of construction works and structural elements for a room with a technological space "meeting room»:

Floor $\left(\mathbf{F}_{\text {MEETRM }}\right)$ :

by $\mathbf{P}_{1}$ : 11-01-037 Carpeting $-29.4 \mathrm{~m}^{2}$;

by $\mathbf{P}_{2}$ : 08-01-003-01 Waterproofing of walls, foundations: horizontal cement with liquid glass - $29.4 \mathrm{~m} 2$;

by $\mathbf{P}_{3}$ : floor structure.

Ceiling $\left(\mathbf{R}_{\text {MEETRM }}\right)$ :

by $\mathbf{P}_{1}: \mathbf{P}_{1}\left(\mathbf{P}_{2}\right)$;

by $\mathbf{P}_{2}$ : 15-01-053-01 Arrangement of suspended sound-absorbing ceilings in a semihidden suspension system $-29.4 \mathrm{~m}^{2}$;

by $\mathbf{P}_{3}$ : floor structure.

Walls $\left(\mathbf{W}_{\text {MEETRM }}\right)$ :

by $\mathbf{P}_{1}$ : 15-06-001 Wallpapering - $84.1 \mathrm{~m}^{2}$;

by $\mathbf{P}_{2}: \mathbf{P}_{2}\left(\mathbf{P}_{1}\right)$;

by $\mathbf{P}_{3}$ : 08-04-001 Installation of partitions made of lightweight concrete slabs: in 2 layers with a floor height of up to $4 \mathrm{~m}-52.9 \mathrm{~m} 2$.

That is, the result of the application of the method is a parametric description of building structures as a set of necessary general construction works, with a detail close to the estimate documentation drawn up based on an already finished construction project. Customers at the stage of drawing up a technical assignment can receive specific construction work, work out various options for the use of building materials, analyze economic efficiency, determine the need for building materials, analyze resource availability and construction time.

A detailed technical task formed according to the proposed method can help designers use generative design tools with a ready-made base of initial construction information about the building being erected. As a result, a situation is created in which designers are freed from the routine process of identifying construction work and structural elements, and act as experts who must confirm or deny the parametric description of building structures proposed by the customer.

\section{Conclusion}

The proposed method can help change the traditional design process and make it possible to take full advantage of modern generative design technologies. Customers of construction 
projects will be able, at the early stages of implementing investment and construction projects, to get an idea of the general construction work for the construction of a building or structure, analyze options for identifying construction work and structural elements, analyze economic efficiency, construction time, and so on. Designers, on the other hand, are freed from the routine processes of selecting building materials, and act as experts who need to confirm or deny customer proposals. Designers also can more effectively use generative design technologies and receive at the output not only options for planning solutions, but a practically finished project.

Analysis of the results got during the approbation of the method showed the need for element-by-element consideration of construction work and structural elements of capital construction objects in order to break them down into "influencing" and "not affecting" the total cost of construction. That is, having information about the building elements, the cost of which depends on the design decisions made, having determined the criteria, it becomes possible to describe them parametrically by identifying construction work and structural elements, already at the stage of drawing up the technical task. This allows customers of work, already on early investment construction projects, to form an idea of the work for the construction of a construction object, and allows designers to better understand the requirements of customers.

\section{References}

1. Volkov A., Shilova L., Cyber-Physical Systems in Construction for Sustainable Urban Development, E3S Web of Conferences, 143, 01019 (2020)

2. Kostin A. N., Flexible change of automation degree as an allocator of functions between human and automatics, Institute of Psychology of the Russian Academy of Sciences, Moscow, -pp. 62-71 (1991)

3. Ginzburg A., Shilov L., Shilova L., The methodology of storing the information model of building structures at various stages of the life cycle, Journal of Physics: Conference Series, 1425(1), 012156 (2020)

4. Ginzburg A., Sustainable Building Life Cycle Design, 15th International Conference on Topical Problems of Architecture, Civil Engineering, Energy Efficiency and Ecology, TPACEE-2016; Tyumen State University of Architecture and Civil Engineering: MATEC Web of Conferences, Volume 73, 02018 (2016)

5. Kuzina O.N., Information modeling of construction object cost at each stage of lifecycle, Scientific and Technical Volga region Bulletin. № 1. -pp. 107-111 (2019)

6. Ginzburg A.V., LE IM: Living Environment Information Modelling, International Scientific Conference Environmental Science for Construction Industry, ESCI 2018; Ho Chi Minh City; Viet Nam: MATEC Web of Conferences, Volume 193, 05030 (2018)

7. Ginzburg A., Queuing Systems in Management Construction, Applied Mechanics and Materials Vols. 405-408 (2013), Trans Tech Publications, Switzerland, 2013, -pp. 3352-3355 (2013)

8. Ginzburg A., Ryzhkova A., Accounting "pure" risks in early stage of investment in construction projects with energy efficient technologies in use, Applied Mechanics and Materials Vols. 672-674 (2014), Trans Tech Publications, Switzerland, -pp. 2221-2224 (2014)

9. Garyaeva V.V., Garyaev N.A., Integrated assessment of the technical condition of the housing projects on the basis of computer technology, Computing in Civil and Building Engineering Proceedings International Conference 1336 (2014) 
10. Kisel' T.N., Tyurin I.A., Features of the introduction of information modeling technologies at the Russian enterprises of the investment and construction sphere, Financial Economy, №3, -pp. 151-155 (2020)

11. Tyurin I., Methods of computer modeling of cost models for buildings, IOP Conf. Ser.: Mater. Sci. Eng. 2020869062031 (2020)

12. Pilyay A., Shilova L. The use of normative basis for the construction cost for introduction of 5D BIM in Russia, IOP Conference Series: Materials Science and Engineering, 365(6), 062009 (2018)

13. Methodology for determining the estimated cost of construction, reconstruction, overhaul, demolition of capital construction, works to preserve cultural heritage (historical and cultural monuments) of the peoples of the Russian Federation on the territory of the Russian Federation, Order of the Ministry of Construction, Housing and Utilities of the Russian Federation of August 4, 2020 №. 421/pr (2020)

14. Tyurin I. A., Ginzburg A. V., Increasing the economic efficiency of design and construction solutions due to the automated identification of construction works and structural elements of information models, IOP Conf. Ser.: Mater. Sci. Eng. 1083 012076 (2020)

15. Tyurin I. A., Automation identification of construction work and structural elements in BIM development, OP Conf. Ser.: Mater. Sci. Eng. 2020913042010 (2020) 